\title{
Prune belly syndrome-report of 47 cases
}

\author{
C R J WOODHOUSE, P G RANSLEY, AND D INNES-WILLIAMS \\ St Peter's Hospitals and The Hospital for Sick Children, Great Ormond Street, London
}

SUMMARY Forty-seven cases of prune belly syndrome in children born between 1948 and 1977 are described. They have been classified into three groups according to the state of the urinary tract in the neonatal period. The results achieved in these cases form the basis of our present management. In group 1 , the most severely affected, early death is inevitable. In group 2 the children are ill as neonates; high diversion is often required and later reconstruction may be possible. Group 3 patients are healthy as neonates and little reconstructive surgery is required. The prognosis in groups 2 and 3 is good. Half the group 2 children and three-quarters of the group 3 children grew up normally with satisfactory renal function and health. It is important to establish free drainage of the urinary tract and avoid infection.

The prune belly syndrome, in its pure form, comprises complex malformations of the urinary tract, bilateral undescended testes, and absence of the anterior abdominal wall muscles. Examples are seen with abdominal wall muscles present to a varying degree; such boys are called 'pseudo-prunes', but this term must not be allowed to mislead as good muscles are not necessarily a sign of a good urinary tract. A similar condition can be present in girls although it is rare, and obviously without the undescended testes.

In this paper we review 47 boys with this syndrome (including 10 pseudo-prunes) born between 1948 and 1977, and describe our present scheme of management.

\section{Patients and methods}

The notes of the 50 patients with the prune belly syndrome seen in these hospitals, born between 1948 and 1977, were reviewed. Twenty-six cases were referred in the first year of life and 24 later. Thirtytwo cases are still under our review and 6 others have died. Contact was made with the medical teams caring for the remaining 12 , but adequate information was available for only nine. Our present management is based on the results achieved in the 47 boys for whom there was detailed follow-up information.

\section{Diagnosis}

The diagnosis was generally obvious at birth, but in 9 boys it was delayed for between 2 months and
9 years, despite the fact that some of them had no abdominal wall muscles.

In none was there a family history of the syndrome. Two patients each had an unaffected male twin, one of whom died 8 hours after birth from respiratory distress syndrome. One mother had a strong family history of an unspecified renal disease.

There had been no particular problems in pregnancy or labour. One mother was hypertensive and another had taken thalidomide.

Other major congenital abnormalities were rare

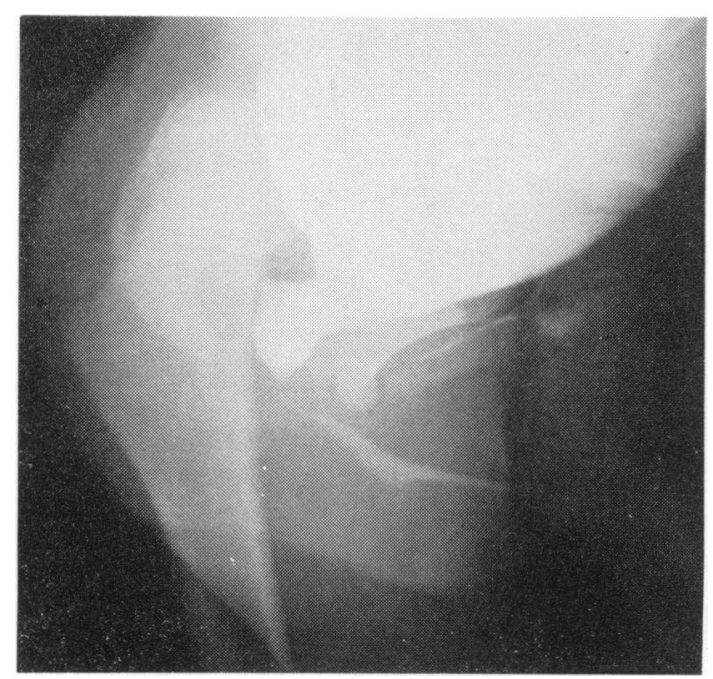

Figure Micturating cystourethrogram showing the widely dilated posterior urethra with a fairly narrow anterior urethra. 
and were not necessarily associated with severe urinary tract abnormalities. A universal mesentary was a frequent finding. Minor abnormalities especially of the bones and joints were common.

The radiological appearances are variable and have been extensively described elsewhere. ${ }^{12}$ It is essential to realise that, whatever the aetiology of the condition, the very dilated and bizarre appearances of the urinary tract are not necessarily signs of obstruction. If obstruction is present, it is most often in the membranous urethra. The prostatic urethra is nearly always dilated, partly because of the incomplete prostatic development. ${ }^{3}$ The remainder of the urethra shows a variable degree of narrowing (Figure). In severely affected patients it may be completely atretic. In milder cases it often appears to be of normal calibre and yet still inadequate for complete bladder emptying. The term 'functional obstruction' seems appropriate if the urethra produces more resistance than the weak detrusor can overcome. ${ }^{4}$

\section{Results}

The management and prognosis are dependent on the condition of the urinary tract at birth. We have found it useful to classify cases on the basis of renal function in the neonatal period (Table 1)..$^{5}$

Group 1. The 5 patients in this group were all diagnosed and referred at birth. They were ill, oliguric, and serial plasma urea and creatinine estimations showed rapidly worsening renal function. One had a patent urachus.

High diversion was carried out but all died within a month. Six of 8 kidneys for which radiological information was available were non-functioning and 2 were barely opacified. It seems likely that these children were born with insufficient renal tissue, and diversion did not improve the condition.

Group 2. Thirteen patients presented as neonatal emergencies and are defined as group 2. Their kidneys excreted poorly on urography, often with only one side working. The collecting systems were grossly dilated and easily became infected. In the first few days of life the plasma urea concentration rose slowly.

Table 1 Clinical classification of 47 cases of the prune belly syndrome

\begin{tabular}{lll}
\hline Group & \multicolumn{1}{c}{$\begin{array}{l}\text { Number } \\
\text { of cases }\end{array}$} \\
\hline 1 & $\begin{array}{c}\text { Perinatal death, often with hypoplastic or } \\
\text { atretic urethra }\end{array}$ & 5 \\
2 & $\begin{array}{c}\text { Neonatal emergency presentation with } \\
\text { infection and gross urinary tract dilatation } \\
\text { Well in the neonatal period. Good renal } \\
\text { function despite very abnormal radiology }\end{array}$ & 13 \\
\hline
\end{tabular}

High diversion was carried out in 12 cases. Both kidneys were explored and if there was any sign of functioning renal tissue a pyelostomy or a loop ureterostomy was performed. In 10 patients renal function was stabilised and in 6 reconstruction of the urinary tract was attempted although normal micturition and stable renal function were achieved in only three.

The 13th case was complicated by tuberculosis in mother and baby, his renal function was never properly stabilised, and he died in uraemia at age 14 .

Group 3. Most (29) patients were in group 3. They were well at birth and had stable renal function in the first few weeks of life. Intravenous urography showed the characteristically bizarre urinary tract but with good excretion. If there was obstruction in this group it was generally in the urethra. It was relieved endoscopically either by resection of a narrow ring (6 operations), or by full length urethrotomy (14 operations). Formal urethroplasty was performed in one case.

The posterior urethra was usually wide open, but in 6 cases it was not, and bladder neck Y-V plasty or resection was needed.

Only if proper bladder emptying did not preserve or improve the upper tracts was upper tract surgery considered.

Virtually normal growth occurred unless there were other unrelated problems. Urinary infection frequently led to temporary deterioration in renal function.

The boys in our series are now aged between 4 and 34 years. Seventeen are into or past their pubertal growth spurt. The present results are shown in Table 2.

During the growth spurt that accompanies puberty, the renal function remained stable. Urethral obstruction sometimes recurred or presented for the first time later in childhood and could be reversed by urethrotomy. Of the patients with renal complications, the condition of only 3 deteriorated as teenagers.

\section{Recommendations for management}

It should always be possible to make the diagnosis at birth. A combination of bilateral cryptorchidism with any disturbance of micturition or renal function should bring the diagnosis to mind.

Management must be shared between the physician and the surgeon. The prune urinary tract is particularly susceptible to infection and so investigations are best carried out at centres equipped to deal with the surgical consequences of the syndrome. 
Table 2 Present condition of 42 group 2 and group 3 patients with prune belly syndrome

\begin{tabular}{lll}
\hline Condition & \multicolumn{2}{l}{ No of patients } \\
\cline { 3 - 3 } & Group 2 & Group 3 \\
\hline $\begin{array}{l}\text { Healthy (normal levels of blood urea and } \\
\text { creatinine, normal micturition, and } \\
\text { negligible urinary infection) }\end{array}$ & 3 & 22 \\
$\begin{array}{l}\text { Healthy but with diversion } \\
\begin{array}{l}\text { Unsatisfactory } \\
\text { Hypertensive }\end{array}\end{array}$ & 4 & \\
$\begin{array}{l}\text { Early renal failure and diversion } \\
\text { End stage renal failure }\end{array}$ & 3 & 2 \\
$\begin{array}{l}\text { Renal calculi and psychiatric problems } \\
\text { Postoperative respiratory arrest leading } \\
\text { to brain damage }\end{array}$ & 2 & 1 \\
$\quad \begin{array}{l}\text { Teratoma of the testis } \\
\text { Died (in uraemia aged 14 years) }\end{array}$ & 1 & 1 \\
\hline
\end{tabular}

An early assessment of renal function is now made by measurement of plasma urea and creatinine concentrations, chromium EDTA clearance, and DMSA scan. Urinary tract ultrasound, if possible before and after voiding, is the best measure of dilatation. Intravenous urography has disappointing results in the neonate although in the larger child does give valuable anatomical information.

Rapid deterioration is still managed by high diversion to allow renal function to stabilise. If this fails to improve function the infant has insufficient renal parenchyma to support life.

For the remainder it is essential to establish complete bladder emptying. Cysto-urethroscopy is performed under general anaesthetic and urethrotomy is made if required.

As the child grows renal function and urinary infection are closely watched. Renal function is remarkably good in these boys considering the poor material with which they are born. It is however, highly susceptible to infection and to even the modest increases in back pressure that their collecting systems can generate. Concentration defects and renal osteodystrophy will occasionally be seen. Bacteriuria is treated vigorously to prevent renal failure. Persistent infection is a sign of poor drainage, generally at urethral level, and surgical correction is required.

In group 3 cases we follow a policy of minimal surgical interference. ${ }^{6}$ Chronically infected and poorly functioning kidneys which fail to improve with adequate drainage are removed. Apart from this, upper tract surgery is undertaken only for proved obstruction and after lower tract obstruction has been eliminated.

In group 2 patients reconstruction of the urinary tract should be attempted before the boy goes to school. There must be some evidence of ureteric muscle activity for there to be any hope of success; we have found that tailoring of a wide aperistaltic tube does not restart peristalsis but leads to a narrow aperistaltic tube.

The most pleasing aspect of this syndrome is the manner in which the boys develop: despite gross urinary tract abnormalities they grow normally. Unless other problems prevent it, they should go to normal schools and take part in the usual school activities.

The absence of anterior abdominal muscles does not appear to be a handicap and is compensated for by other muscle groups. The only movement they cannot make is to sit up from the supine position; they must roll over to one side first. Support for the abdominal wall is not necessary. Three boys had abdominal plications: it did little to improve function or appearance and we no longer consider it necessary. Likewise, we do not use abdominal corsets. As the child grows, the wrinkled abdominal appearance is replaced by a premature 'beer belly'.

\section{The testes}

By definition, the testes were always undescended. They were most commonly found just below the lower pole of the kidney. In patients with some abdominal muscle (the so called pseudo-prunes) they were lower and even in the inguinal canal.

The diagnosis of prune belly syndrome should be reconsidered critically in any boy with normally descended testes.

We have brought down testes at the same time as definitive ureteric surgery. If it had become clear that ureteric surgery would not be needed, generally at about 7 years old, orchidopexy was performed. Except with a very low testis, surgery involves division of the testicular artery, blood supply being maintained by the artery to the epididymis and a pedicle of peritoneum.

Reasonable puberty has occurred in 12 boys. Although the prune testis is said to be a better organ than other types of cryptorchid, ${ }^{7}$ we have seen only one boy develop wide distribution of body hair and masculine muscles. No boy is known to have fathered a child. Testicular function is currently being investigated and the results will be presented later.

One boy who had married and had normal sexual intercourse, has developed teratoma of the testis. ${ }^{8}$ This experience must mean that a careful watch should be kept on the testes in this syndrome.

\section{Discussion}

The prune belly syndrome has been well described in all its forms.156910 The cause of the congenital abnormality is not known, but it has recently been suggested that it is a 2-step autosomal dominant 
mutation with sex-linked expressions, partially mimicking X-linkage. ${ }^{11}$

We do not agree with the view that it is a nonspecific response to massive abdominal distension in utero. ${ }^{12}$ In group 1 cases the urachus is often patent and so bladder distension will not occur. Likewise in group 3, many patients have no evidence of urethral obstruction at birth. Radiographic and cystoscopic appearances in boys with severe obstruction from posterior urethral valves are quite different from those of the prune belly syndrome.

In one case reported by Smythe a male fetus with idiopathic intrauterine abdominal and bladder distension was born with apparent prune belly syndrome. ${ }^{13}$ However, the boy was physically and radiographically normal at one year which suggests that distension alone does not cause the syndrome.

The stagnant urinary tract of the prune belly syndrome is prone to infection leading to septicaemia, especially in infancy. Throughout life two objectives are paramount: to establish free drainage of the urinary tract and to keep it clear of infection. Success in the first objective is the most important step in the achievement of the second.

Because the syndrome is rare, few centres have seen enough cases to appreciate its broad spectrum. As a result considerable controversy remains about the management. Some surgeons advocate an aggressive approach, aiming for complete correction of the urinary anomalies, ${ }^{14-16}$ while others prefer a more conservative approach. ${ }^{5} 17$

The prognosis ultimately depends on the condition of the kidneys at birth. Classification based on neonatal urinary tract function is reasonable and has allowed a more rational approach to management.

Group 1 patients have a hopeless prognosis. None the less few surgeons would be willing to stand by and do nothing but will attempt a high diversion.

Group 2 patients are born with poor kidneys but with the potential to support life. Early drainage of the kidneys by high diversion is generally essential.

Later reconstruction of urinary tracts may be possible. We have attempted it rather late and the results have been disappointing. The case for earlier reconstruction now seems strong. ${ }^{18}$

In the group 3 patients, we were often surprised by the very good function that was produced by radiologically poor kidneys. These boys do well despite their huge bladders and ureters. We did not find aggressive reconstruction necessary. ${ }^{6}$ It is essential to establish complete bladder emptying at the start. Even in patients presenting late, renal function could be improved by establishing proper bladder emptying. Upper tract surgery was less often indicated and was less rewarding, although upper tract deterioration could be halted.

Boys in group 3 have a good prognosis for life and health, with a remarkably small handicap. Most have grown up normally and can compete with their peers. Seventeen have completed puberty and, with one exception, are mature and well motivated adults.

\section{References}

1 Williams D I. The prune belly syndrome. In: Encyclopaedia of urology in childhood. Encyclopaedia of Urology XV Supplement. Berlin: Springer, 1974: 230-7.

2 Berdon W E, Baker D H, Wigger H J, Blanc W A. The radiologic and pathologic spectrum of the prune belly syndrome. Radiol Clin North Am 1977; 15: 83-92.

3 Nunn I N, Stephens F D. Triad syndrome: a composite anomaly of the abdominal wall, urinary system, and testes. J Urol 1961 ; 86: 782-94.

4 Perlmutter A D, Retik A B. Letter: Prune belly syndrome. Am J Dis Child 1970; 119: 191.

5 Williams D I, Parker R M. The role of surgery in the prune belly syndrome. In: Johnston J H, Goodwin W E, ed. Reviews in paediatric urology. Amsterdam: Excerpta Medica, 1974: 315-31.

6 Woodhouse C R J, Kellett M J, Williams D I. Minimal surgical interference in the prune belly syndrome. $B r J$ Urol 1979; 51 : 475-80.

7 Hinman F, Jr. Alternatives to orchidopexy. J Urol 1980; 123: $548-51$.

8 Woodhouse C R J, Ransley P G. Teratoma of the testis in the prune belly syndrome. $B r J U r o l$ in press.

9 Williams D I, Burkholder G V. The prune belly syndrome. J Urol 1967; 98: 244-51.

10 Wigger $\mathrm{H} \mathrm{J}$, Blanc $\mathrm{W}$ A. The prune belly syndrome. In: Sommers S C, Rosen P P, eds. Pathology annual, part 1. New York: Appleton-Century-Crofts, 1977: 17-39.

11 Riccardi V M, Grum C M. The prune belly anomaly. J Genet Med 1977; 14: 266-70.

12 Pagon R A, Smith D W, Shepard T H. Urethral obstruction malformation complex: a cause of abdominal muscle deficiency and the prune belly. J Pediatr 1979; 94: 900-6.

13 Smythe A R. Ultrasonic detection of fetal ascites and bladder dilatation with resulting prune belly. $J$ Pediatr 1981; 98: 978-80.

14 Welch K J, Kearney G P. Abdominal musculature deficiency syndrome: prune belly. J Urol 1974; 111: 693-700.

15 Waldbaum R S, Marshall V S. The prune belly syndrome: a diagnostic therapeutic plan. J Urol 1970; 103: 668-74.

16 Woodard J R, Parrott T S. Reconstruction of the urinary tract in prune belly uropathy. J Urol 1978; 119: 824-8.

17 Palmer J M, Tesluk H. Ureteral pathology in the prune belly syndrome. J Urol 1974; 111 : 701-7.

18 Hendren W H. Restoration of function in the severely decompensated ureter. In: Johnston J H, Scholtmeijer R J, eds. Problems in paediatric urology. Amsterdam: Excerpta Medica, 1972: 1-57.

Correspondence to $\mathrm{C}$ R J Woodhouse FRCS, Academic Unit, Institute of Urology, 172 Shaftesbury Avenue, London WC2H 8JE.

Received 18 June 1982 